\title{
Nitrogen Regulation of Glutamine Synthetase in Neurospora crassa
}

\author{
By IRMA VICHIDO, YOLANDA MORA, CARMEN QUINTO, \\ RAFAEL PALACIOS AND JAIME MORA \\ Departamento de Biología Molecular, Instituto de Investigaciones Biomédicas, \\ Universidad Nacional Autónoma de México, Apdo Postal 70228, México 20, D.F.
}

(Received 29 December 1977)

\begin{abstract}
A higher activity of glutamine synthetase (EC 6.3.1.2) was found in Neurospora crassa when $\mathrm{NH}_{4}{ }^{+}$was limiting as nitrogen source than when glutamate was limiting. When glutamate, glutamine or $\mathrm{NH}_{4}{ }^{+}$were in excess, a lower activity was found. Immunological titration and sucrose gradient sedimentation of the enzyme established that under all these conditions enzyme activity corresponded to enzyme concentration and that the octamer was the predominant oligomeric form. When $N$. crassa was shifted from nitrogen-limiting substrates to excess product as nitrogen source, the concentration of glutamine synthetase was adjusted with kinetics that closely followed dilution by growth. When grown on limiting amounts of glutamate, a lower oligomer was present in addition to the octameric form of the enzyme. When the culture was shifted to excess $\mathrm{NH}_{4}^{+}$, glutamine accumulated at a high rate; nevertheless, there was only a slow decrease in enzyme activity and no modification of the oligomeric pattern.
\end{abstract}

\section{INTRODUCTION}

Numerous reports have established in prokaryotes a role of glutamine synthetase in the regulation of nitrogen metabolism, including its own synthesis (Foor, Janssen \& Magasanik, 1975; Stadtman \& Ginsburg, 1974; Streicher, Bender \& Magasanik, 1975; Tyler, De Leo \& Magasanik, 1974; Magasanik et al., 1974; Weglenski \& Tyler, 1977; Wohlhueter, Schutt \& Holzer, 1973). This enzyme has also been thoroughly characterized from eukaryotic organisms (Meister, 1974; McParland et al., 1976; Sims, Toone \& Box, $1974 a, b$; Tiemeier \& Milman, 1972 ) and there have been reports on its regulation in Saccharomyces (Kohlaw, Dragert \& Holzer, 1965), Candida (Ferguson \& Sims, $1974 a, b$ ), filamentous fungi (Pateman, 1970), cultured mammalian cells (Kulka \& Cohen, 1973; Milman, Portnoff \& Tiemeier, 1975) and chick retina (Moscona, Frankel \& Moscona, 1972; Sarkar \& Griffith, 1976).

Studies in our laboratory have established in Neurospora crassa a metabolic link of glutamine biosynthesis with its distribution to several amino acids, mainly arginine, as well as with nitrogen catabolism. If growth is restricted, nitrogen accumulates, mainly as glutamine and arginine, and catabolism of the latter amino acid is impaired (Mora et al., 1978; Espín \& Mora, 1978). Since glutamine is the nitrogen donor for the synthesis of arginine, we have studied the regulation of glutamine synthesis. This paper reports on the nitrogen regulation of glutamine synthetase in $N$. crassa. We have previously. purified and partially characterized the enzyme (Palacios, 1976) and specific antibodies against it have been obtained (Palacios, Campomanes \& Quinto, 1977). 


\section{METHODS}

Organism and growth. Neurospora crassa wild type 74-A was grown on Vogel's minimal medium N (Vogel, 1964) supplemented with $1 \cdot 5 \%(\mathrm{w} / \mathrm{v})$ sucrose; $\mathrm{NH}_{4} \mathrm{NO}_{3}$ was replaced by other nitrogen sources as indicated in the text and figure legends. Mycelium was grown from a conidia inoculum (Sánchez, Martínez \& Mora, 1972 ) in liquid medium sparged with moist air at $25^{\circ} \mathrm{C}$. In certain experiments, nitrogen limitation was achieved by supplying different nitrogen compounds at a constant rate using a syringe attached to a pump (Limón-Lason et al., 1977).

Glutamine synthetase activity. Mycelium was filtered (Whatman no. 41 paper) and washed with distilled water. Acetone powders were prepared from the mycelium, ground with dry ice and homogenized at $4{ }^{\circ} \mathrm{C}$

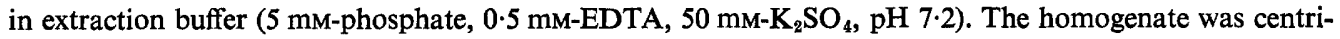
fuged for $15 \mathrm{~min}$ at $12500 \mathrm{~g}$ and the supernatant was used as the source of enzyme. Glutamine synthetase [EC 6.3.1.2; L-glutamate:ammonia ligase (ADP-forming)] was measured by its synthetase and transferase activities as described by Ferguson \& Sims (1974a). Protein was determined by the method of Lowry $e t a l$. (1951).

Glutamate and glutamine pools. Mycelium was harvested by filtration, washed with distilled water and homogenized in $20 \mathrm{ml} 80 \%(\mathrm{v} / \mathrm{v})$ ethanol containing $0.5 \mu \mathrm{Ci}$ of $\mathrm{L}-\left[\mathrm{U}-{ }^{14} \mathrm{C}\right.$ ]glutamine. The homogenates were boiled for $10 \mathrm{~min}$, cooled and filtered. The alcohol-insoluble material was re-extracted in $20 \mathrm{ml} 80 \%(\mathrm{v} / \mathrm{v})$ ethanol. The filtrates were lyophilized and the dried samples were resuspended in $2 \mathrm{ml}$ deionized water plus $0.2 \mu \mathrm{Ci}$ of $\mathrm{L}-\left[\mathrm{U}-{ }^{14} \mathrm{C}\right]$ glutamic acid. Glutamic acid and glutamine were separated and measured using the method of Yemm \& Cocking (1955) as modified by Ferguson \& Sims (1974a). Glutamic acid and glutamine concentrations were calculated by dilution of the specific radioactivity of the labelled compounds.

Preparation and characterization of anti-glutamine synthetase antibodies. Glutamine synthetase was purified to homogeneity by DEAE-cellulose chromatography followed by affinity chromatography on anthranilatebound Sepharose (Palacios, 1976). Rabbits were immunized as previously described (Palacios et al., 1977) and the serum was fractionated with ammonium sulphate to obtain the total $\gamma$-globulin fraction. This fraction was further purified by affinity chromatography using a matrix of $N$. crassa glutamine synthetase bound to Sepharose. Different experimental criteria such as double immunodiffusion, immunoelectrophoresis, immunoprecipitation of enzyme activity and immunoprecipitation of 'in vivo' labelled $N$. crassa extract indicated that this antibody fraction was specific for $N$. crassa glutamine synthetase (Palacios et al., 1977).

Immunochemical titration of glutamine synthetase activity. Both direct and indirect immunological titrations were done. In the direct procedure, samples of $N$. crassa extracts containing a constant amount of glutamine synthetase activity were incubated for $90 \mathrm{~min}$ at $4{ }^{\circ} \mathrm{C}$ in the presence of extraction buffer (as above, but also containing $2 \mathrm{mg}$ bovine serum albumin $\mathrm{ml}^{-1}$ ) with various amounts of anti-glutamine synthetase total $\gamma$-globulin fraction. The final volume was $0.5 \mathrm{ml}$. After incubation, the reaction mixture was centrifuged for $5 \mathrm{~min}$ at $10000 \mathrm{~g}$ and glutamine synthetase activity (transferase) was measured in the supernatant. In the indirect procedure, $N$. crassa extracts containing a constant amount of glutamine synthetase activity were incubated for $90 \mathrm{~min}$ with $25 \mu \mathrm{g}$ purified anti-glutamine synthetase antibody. Anti-rabbit $\gamma$-globulin was then added at different concentrations and incubation was continued for another $90 \mathrm{~min}$. The reaction mixture was centrifuged and enzyme activity (transferase) was measured in the supernatant.

Preparation of glutamine synthetase labelled in vivo. To a culture of $N$. crassa grown on 5 mm-glutamate as the sole nitrogen source was added $\left[{ }^{3} \mathrm{H}\right]$ methionine $\left(5 \mu \mathrm{Ci} \mathrm{ml}{ }^{-1}\right.$; sp. act. $\left.10 \mathrm{Ci} \mathrm{mmol}^{-1}\right)$ for 60 min. Radioactive enzyme was then purified as previously described (Palacios, 1976) but using two consecutive steps of affinity chromatography on anthranilate-bound Sepharose. The specific radioactivity of the purified preparation was $1.2 \times 10^{6}$ c.p.m. (mg protein) $)^{-1}$.

Sedimentation of glutamine synthetase. Samples of $N$. crassa extracts were layered on to 5 to $20 \%(\mathrm{w} / \mathrm{v})$ continuous sucrose gradients prepared in extraction buffer (see above) and centrifuged for $12 \mathrm{~h}$ at $284000 \mathrm{~g}$ in a SW40 Beckman rotor. The gradients were then fractionated and glutamine synthetase activity (transferase) was measured in each fraction. The molecular weight was calculated as previously described using globular proteins as markers (Palacios, 1976). In some experiments, radioactive glutamine synthetase was included as an internal marker.

\section{RESULTS}

\section{Substrates and product of glutamine synthetase as nitrogen source}

Doubling times for the growth of $\mathrm{N}$. crassa strain 74-A on glutamate, glutamine or $\mathrm{NH}_{4}{ }^{+}$ as nitrogen source were 3,2 and $2.5 \mathrm{~h}$, respectively (Fig. $1 \mathrm{a}$ ). When both glutamate and $\mathrm{NH}_{4}{ }^{+}$were present in excess, the doubling time was similar to that with only $\mathrm{NH}_{4}{ }^{+}$in 

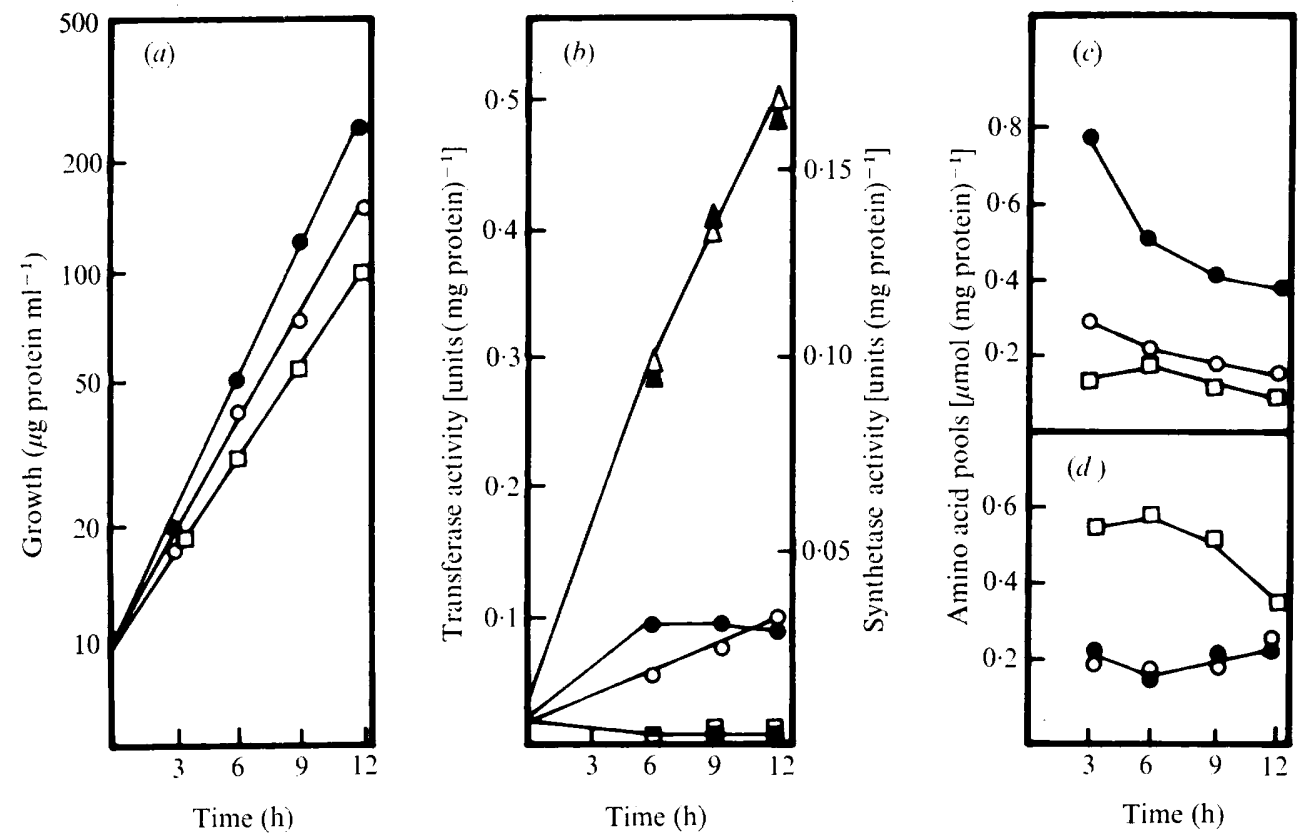

Fig. 1. Growth, glutamine synthetase activity and amino acid pools of $N$. crassa grown on different nitrogen sources. Strain 74-A was grown in Vogel's minimal medium (containing $\mathrm{NH}_{4} \mathrm{NO}_{3}$ ) or with 5 mM-glutamine or 5 mM-glutamate as nitrogen source instead of $\mathrm{NH}_{4} \mathrm{NO}_{3}$. (a) Protein content per $\mathrm{ml}$ culture grown on $\mathrm{NH}_{4} \mathrm{NO}_{3}(\bigcirc)$, glutamine $(O)$ or glutamate $(\square)$. (b) Glutamine synthetase specific activity measured by the transferase (open symbols) or synthetase (closed symbols) assays: $\bigcirc, \odot$, grown on $\mathrm{NH}_{4} \mathrm{NO}_{3} ; \square, \boldsymbol{\square}$, grown on glutamine; $\triangle, \boldsymbol{\Delta}$, grown on glutamate. (c) Glutamine pool, symbols as in $(a) .(d)$ Glutamate pool, symbols as in $(a)$.

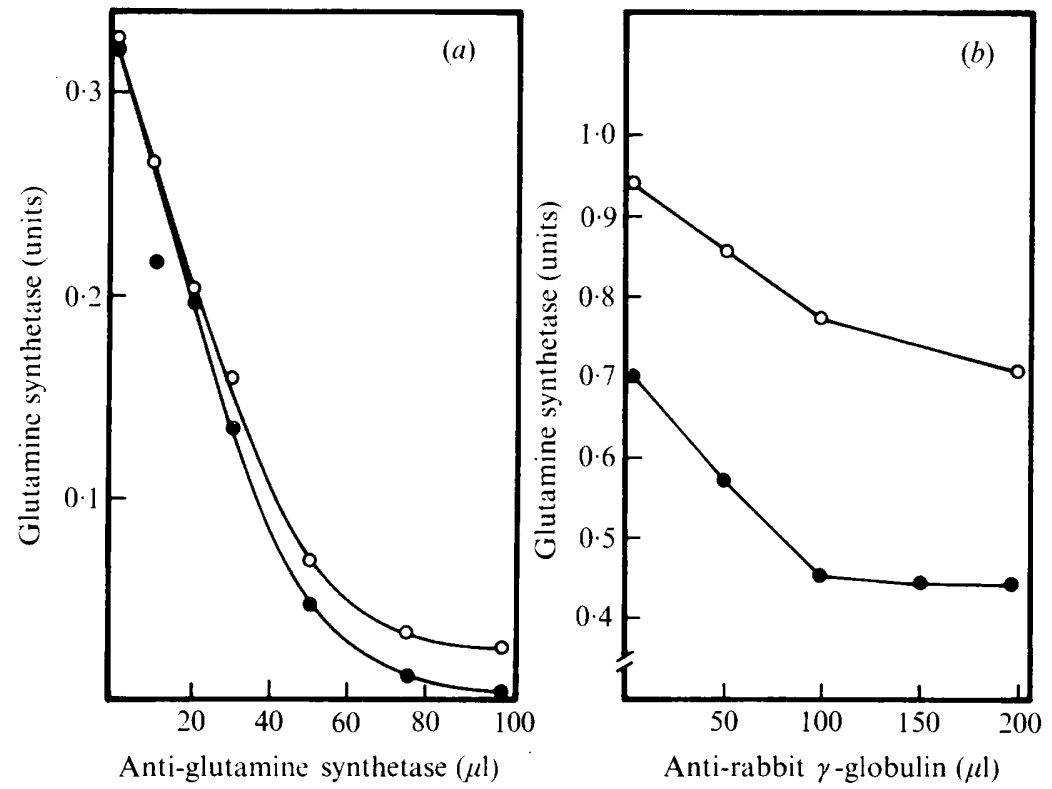

Fig. 2. Immunological titration of glutamine synthetase activity. Neurospora crassa strain 74-A was grown for $12 \mathrm{~h}$ on different nitrogen sources. (a) Direct immunological titration (see Methods) of glutamine synthetase from cultures grown on glutamine $(O)$ or glutamate $(\Theta)$. The titre was obtained by dividing the amount of antibody by the number of enzyme units in the supernatant at $50 \%$ decrease in enzyme activity and was 156 when $N$. crassa was grown on glutamate and 169 when grown on glutamine. (b) Indirect immunological titration (see Methods) of glutamine synthetase grown on $\mathrm{NH}_{4} \mathrm{NO}_{3}(\mathrm{O})$ or glutamate $(O)$. The titre was obtained by subtracting the enzyme activity remaining at high concentrations of anti-rabbit $\gamma$-globulin $(200 \mu \mathrm{l})$ from the initial activity and was 0.26 when $N$. crassa was grown on glutamate and 0.25 when grown on $\mathrm{NH}_{4} \mathrm{NO}_{3}$. 

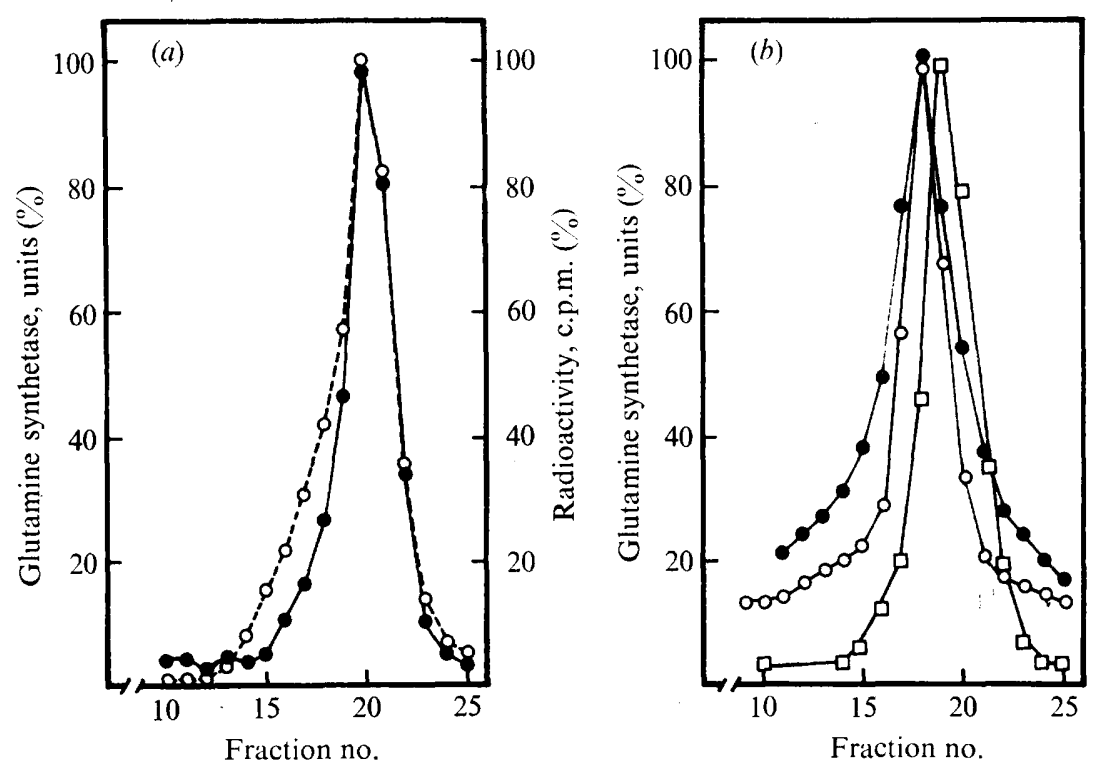

Fig. 3. Sedimentation of glutamine synthetase from $N$. crassa cultures grown on different nitrogen sources. (a) An extract of culture grown on glutamate as nitrogen source was mixed with purified $N$. crassa glutamine synthetase labelled 'in vivo' with $\left[{ }^{3} \mathrm{H}\right]$ methionine, used as a marker for the octameric structure of the enzyme (Palacios, 1976). Of the total glutamine synthetase activity of the mixture, more than $95 \%$ corresponded to that present in the extract. The preparation was layered on to a 5 to $20 \%(\mathrm{w} / \mathrm{v})$ continuous sucrose gradient prepared in extraction buffer (see Methods) and centrifuged for $12 \mathrm{~h}$ at $40000 \mathrm{rev} . \mathrm{min}^{-1}$ in a Beckman SW40 rotor. The gradient was fractionated and enzyme activity $(O)$ and radioactivity (O) were determined in each fraction. Globular proteins were run in separate gradients to calibrate for molecular weight (Palacios, 1976). (b) Extracts from $N$. crassa grown on $\mathrm{NH}_{4} \mathrm{NO}_{3}(\bigcirc)$, glutamine (O) or glutamate $(\square)$ were run in separate gradients and processed as described above. Data were normalized to the fraction with highest activity or radioactivity.

excess (data not shown). Thus, $\mathrm{NH}_{4}{ }^{+}$is limiting when glutamate is the nitrogen source and both substrates are in excess when $\mathrm{NH}_{4}{ }^{+}$is present as the nitrogen source.

Glutamine synthetase activity, as measured by both the transferase and synthetase assays, was very low in spores and increased during outgrowth in the presence of either substrate, reaching levels about fivefold higher when grown in glutamate, i.e. limited $\mathrm{NH}_{4}{ }^{+}$, than when excess $\mathrm{NH}_{4}{ }^{+}$was present (see Discussion). On the other hand, enzyme activity decreased slightly when glutamine was present as nitrogen source. The ratio of synthetase to transferase activities of the enzyme remained constant with glutamate and glutamine as nitrogen sources for growth, whereas with $\mathrm{NH}_{4}{ }^{+}$the ratio was higher at $6 \mathrm{~h}$ (Fig. $1 \mathrm{~b}$ ). The intracellular concentrations of glutamine and glutamate were two to threefold higher when these compounds were used as sole nitrogen source (Fig. 1c,d).

Specific antibodies against glutamine synthetase gave similar titration curves for glutamine synthetase activity when either glutamate or glutamine was used as nitrogen source (Fig. $2 a$ ), indicating that the activity per enzyme molecule was the same under both conditions. In addition, indirect immunological titrations with cell-free extracts from cultures grown on $\mathrm{NH}_{4}{ }^{+}$or glutamate (Fig. $2 b$ ) gave similar antibody titres. Therefore, the differences in the specific activity of glutamine synthetase found in mycelium grown with different nitrogen sources corresponded to differences in enzyme concentration.

The oligomeric structure of the enzyme from cells grown with different nitrogen sources corresponded mainly to the octameric form (Fig. 3). 


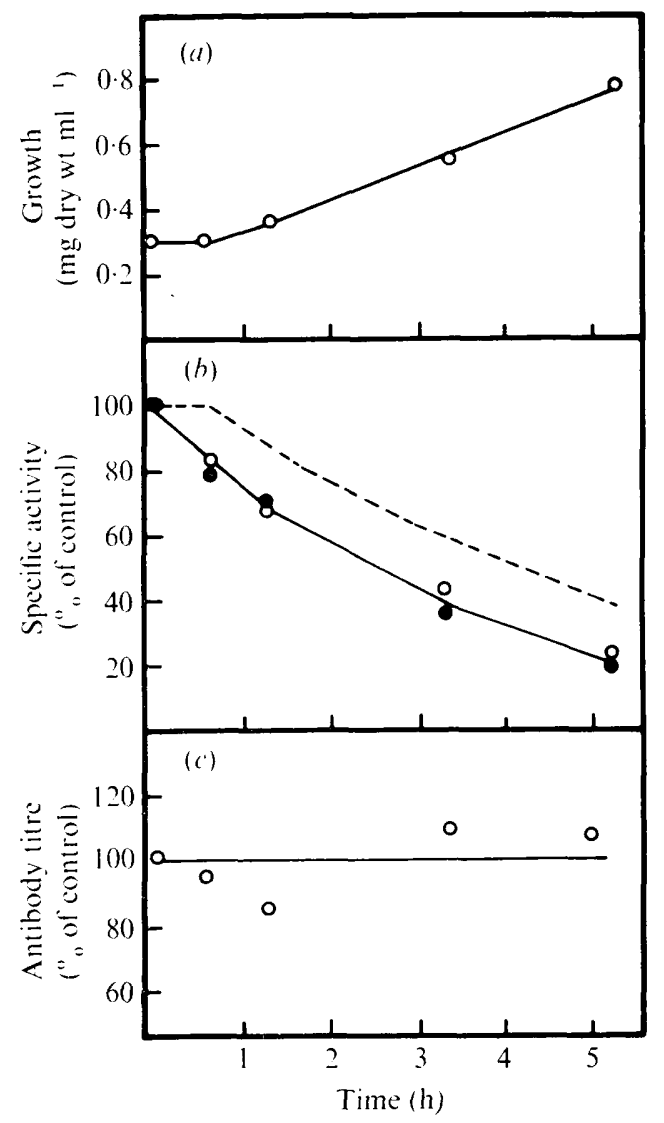

Fig. 4. Shift of $N$. crassa from glutamate to glutamine as nitrogen source. Neurospora crassa was grown for $12 \mathrm{~h}$ with glutamate as the sole nitrogen source. The mycelium was then washed with fresh medium and transferred to medium containing glutamine as the sole nitrogen source. At intervals after the shift, samples were taken to determine: $(a)$ dry weight per ml culture; $(b)$ glutamine synthetase specific activity measured by the transferase $(O)$ or synthetase $(O)$ assays, and expressed as a percentage of the activity at zero time $(0.58$ units of transferase, 0.19 units of synthetase); - - , theoretical dilution of activity expected by growth; (c) direct antibody titre.

\section{Shift from substrate to product of glutamine synthetase as nitrogen source}

To determine the kinetics of adjustment from glutamate to glutamine as nitrogen source, $N$. crassa was grown for $12 \mathrm{~h}$ on glutamate and then transferred to medium containing glutamine as the sole nitrogen source. After a lag of about $40 \mathrm{~min}$, growth resumed and the organism grew exponentially with a doubling time of $3 \mathrm{~h}$ (Fig. $4 \mathrm{a}$ ). The activity of the enzyme (Fig. $4 b$ ) decreased at a faster rate than that expected from dilution during the first minutes; afterwards the decrease in activity corresponded to the theoretical dilution expected by growth. There was no change in the ratio of synthetase to transferase activities of glutamine synthetase. As shown by direct immunoprecipitation of enzyme activity (Fig. 4c), the changes in enzyme specific activity corresponded to changes in enzyme concentration. The enzyme was in the octameric form at different times after the shift (data not shown). 

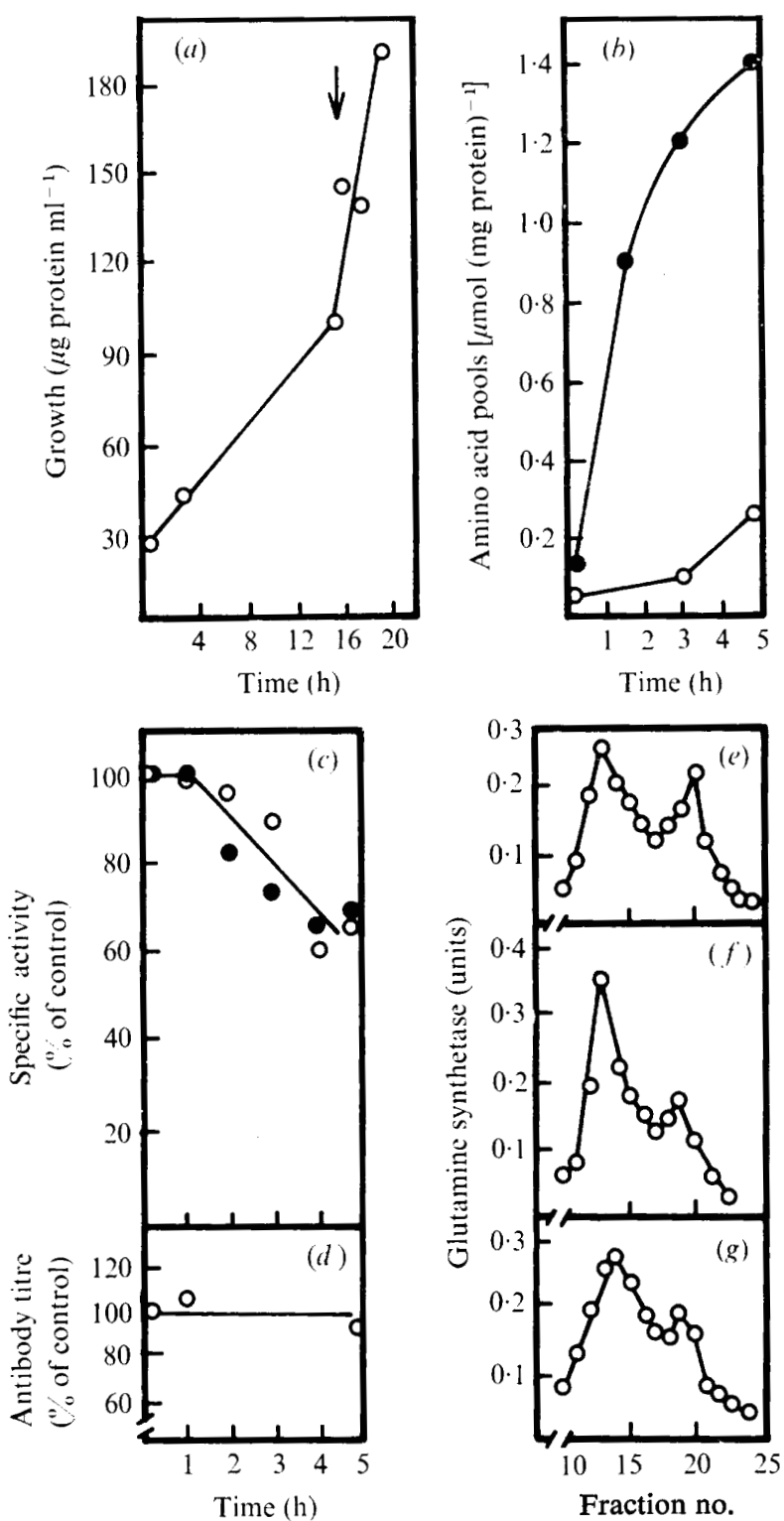

Fig. 5. Shift of $N$. crassa from limiting glutamate to excess $\mathrm{NH}_{4}{ }^{+}$as nitrogen source. Neurospora crassa was grown on limiting glutamate as nitrogen source (see Methods) and (a) total protein per $\mathrm{ml}$ culture was measured during this period. After $15 \mathrm{~h}, \mathrm{NH}_{4} \mathrm{Cl}$ was added at a final concentration of $5 \mathrm{~mm}$ and incubation was continued for a further $5 \mathrm{~h}$. At intervals after the shift, samples were taken to determine: $(b)$ glutamine $(\bullet)$ and glutamate $(O)$ pools; $(c)$ glutamine synthetase specific activity measured by the transferase $(O)$ or synthetase $(\bullet)$ assays, and expressed as a percentage of the activity at zero time (0.53 units of transferase, 0.12 units of synthetase); (d) direct antibody titre; $(e, f, g)$ sedimentation of glutamine synthetase (see Fig. 3) at zero time $(e), 2 \mathrm{~h}(f)$ and $5 \mathrm{~h}(\mathrm{~g})$ after addition of $\mathrm{NH}_{4}{ }^{+}$. 
Shift from limiting glutamate to excess $\mathrm{NH}_{4}{ }^{+}$as nitrogen source

Glutamate was a suboptimal nitrogen source (see Fig. $1 a$ ), and in an attempt to obtain a more severe nitrogen limitation, glutamic acid was added in limiting amounts at a constant rate in fed-batch cultures (Limón-Lason et al., 1977). This resulted in linear growth (Fig. $5 a$ ) and a glutamate pool that was about fourfold lower than that found when glutamate was added in excess to the culture medium. Glutamine synthetase activity was similar to that found with excess glutamate; however, the ratio of synthetase to transferase activities was lower and, in addition to the octameric form of the enzyme, a lower oligomer possibly corresponding to a tetramer was evident (Fig. $5 e$ ).

When, after this nitrogen limitation, excess $\mathrm{NH}_{4}{ }^{+}$was added to the culture medium, the rate of growth increased (Fig. $5 a$ ) and the glutamine pool rose to a level about 20 -fold higher while the glutamate pool remained constant (Fig. $5 b$ ). Enzyme activity maintained its original level during the first hour after the shift and then decreased slowly (Fig. $5 c$ ), which again parallels the dilution expected by growth. Immunological titrations indicated that glutamine synthetase activity corresponded to enzyme concentration (Fig. $5 d$ ). The oligomeric pattern of the enzyme was preserved during this time (Fig. $5 f, g$ ) and the low ratio of synthetase to transferase activities was maintained.

\section{DISCUSSION}

When Neurospora crassa is grown with $\mathrm{NH}_{4}{ }^{+}$as nitrogen source, glutamine synthetase is repressed. When grown on glutamate, this compound is in excess but it must also provide $\mathrm{NH}_{4}{ }^{+}$. Since growth on glutamate is suboptimal, we must conclude that the high activity of glutamine synthetase found under this condition only partially compensates for the $\mathrm{NH}_{4}{ }^{+}$deficiency. When glutamine is present as the sole nitrogen source, this compound is present in excess inside the cell, the organism grows optimally and glutamine synthetase activity is very low. These results led us to investigate the effect of limiting amounts of $\mathrm{NH}_{4}{ }^{+}$ in the regulation of glutamine synthetase by $N$. crassa and, as expected, we found an optimum induction of the enzyme under these conditions. On the other hand, limitation of sucrose in an excess of $\mathrm{NH}_{4}{ }^{+}$results in a low glutamine synthetase activity (Limón-Lason et al., 1977), but this is due to different biosynthetic rates (Quinto, Mora \& Palacios, 1977). Since strain am-1, which lacks biosynthetic glutamate dehydrogenase activity, induces its glutamine synthetase even in the presence of $\mathrm{NH}_{4}{ }^{+}$, a direct effect of this compound can be ruled out (Limón-Lason et al., 1977). We propose, therefore, that the carbon source has a positive role on the regulation of glutamine synthetase whereas glutamine has a negative one. The level at which this regulation occurs is now being investigated.

Ferguson \& Sims (1974b) and Sims et al. (1974a) reported that in Candida utilis glutamine synthetase is present as an octamer when glutamic acid is used as nitrogen source. Addition of $\mathrm{NH}_{4}{ }^{+}$or glutamine to such cells increases the intracellular pool of glutamine and ultimately causes a rapid decrease in enzyme activity concomitant with the appearance of a tetrameric form of the enzyme. This contrasts with our results where the kinetics of the shift from glutamate to glutamine as nitrogen source indicate that the cell adjusts the concentration of glutamine synthetase slowly and no tetrameric form is apparent. Assuming that enzyme synthesis is prevented, the decrease in enzyme concentration is in close correlation with the theoretical dilution expected by growth. A minor contribution to the decrease in enzyme activity is possibly due to degradation or inactivation of the enzyme during the first minutes after the shift. Even in fed-batch cultures where glutamic acid is the limiting nitrogen compound, the addition of $\mathrm{NH}_{4}{ }^{+}$, which results in a large increase in the glutamine pool, causes only a slight decrease in enzyme activity, and for $5 \mathrm{~h}$ after the addition of $\mathrm{NH}_{4}{ }^{+}$, the oligomeric pattern of the enzyme is not modified. Under these limiting conditions two oligomeric forms of the enzyme corresponding to an octamer and a tetramer are present. 
These experiments indicate that mycelium of $N$. crassa does not adjust its glutamine synthetase activity by inactivation and that the slow adaptation is achieved mainly by growth dilution. The tetrameric form that appears under glutamate limitation could be related to the capacity of the cells to fix $\mathrm{NH}_{4}{ }^{+}$at low concentration since the proportion of this oligomeric form increases under conditions where nitrogen limitation is more severe (Limón-Lason et al., 1977).

Although no explanation can be offered at present, the absence of a steady state in glutamine synthetase concentration with glutamate as nitrogen source is possibly related to the fact that Neurospora is a filamentous organism where developmental processes are not excluded.

The authors are grateful to Dr Fernando Bastarrachea and Dr Jaime Martuscelli for critically reading the manuscript. This research was supported in part by grant PCNB 036 from CONACYT (Consejo Nacional de Ciencia y Tecnología, México).

\section{REFERENCES}

Espín, G. \& MoRA, J. (1978). Effect of the deprivation of amino acids on conidia of Neurospora crassa. Journal of General Microbiology 104, 233-240.

FERguson, A. R. \& Sims, A. P. (1974a). The regulation of glutamine metabolism in Candida utilis: the role of glutamine in the control of glutamine synthetase. Journal of General Microbiology 80, 159-171.

FERGuson, A. R. \& Sims, A. P. (1974b). The regulation of glutamine metabolism in Candida utilis: the inactivation of glutamine synthetase. Journal of General Microbiology 80, 173-185.

Foor, F., JANssen, K. A. \& Magasanik, B. (1975). Regulation of synthesis of glutamine synthetase by adenylylated glutamine synthetase. Proceedings of the National Academy of Sciences of the United States of America 72, 4844-4848.

Kohlaw, G., Dragert, W. \& Holzer, H. (1965). Parallel Repression der Synthese von GlutaminSynthese und DPN-abhängiger Glutamat-Dehydrogenase in Hefe. Biochemistry 341, 224-238.

KulKa, R. G. \& CoHEN, H. (1973). Regulation of glutamine synthetase activity of hepatoma tissue culture cells by glutamine and dexamethasone. Journal of Biological Chemistry 248, 6738-6743.

Limón-LAson, J., LARA, M., RESENDIZ, B. \& MoRA, J. (1977). Regulation of glutamine synthetase in fed-batch cultures of Neurospora crassa. Biochemical and Biophysical Research Communications 78, 1234-1240.

Lowry, O. H., Rosebrough, N. J., FarR, A. L. \& RANDALL, R. J. (1951). Protein measurement with the Folin phenol reagent. Journal of Biological Chemistry 193, 265-275.

Magasanik, B., Prival, M., Brenchley, J., Tyler, B., De Leo, A., Streicher, S., Bender, R. \& PARIS, C. G. (1974). Glutamine synthetase as a regulator of enzyme synthesis. Current Topics in Cellular Regulation 8, 119-138.

McParland, R. H, Guevara, J. G., Becker, R. R. \& Evans, H. J. (1976). The purification and properties of the glutamine synthetase from the cytosol of soya-bean root nodules. Biochemical Journal 153, 597-606.
Meister, A. (1974). Glutamine synthetase of mammals. In The Enzymes, vol. 10, p. 699. Edited by P. D. Boyer. New York: Academic Press.

Milman, G., Portnoff, L. S. \& Tiemeier, D. C. (1975). Immunochemical evidence for glutaminemediated degradation of glutamine synthetase in cultured Chinese hamster cells. Journal of Biological Chemistry 250, 1393-1399.

Mora, Y., Espín, G., Willms, K. \& MorA, J. (1978). Nitrogen accumulation in mycelium of Neurospora crassa. Journal of General Microbiology 104, 241-250.

Moscona, M., Frankel, N. \& Moscona, A. A. (1972). Regulatory mechanisms in the induction of glutamine synthetase in the embryonic retina: immunochemical studies. Developmental Biology 28, 229-241.

Palacios, R. (1976). Neurospora crassa glutamine synthetase. Purification by affinity chromatography and characterization of subunit structure. Journal of Biological Chemistry 251, 4787-4791.

Palacios, R., Campomanes, M. \& Quinto, C. (1977). Neurospora crassa glutamine synthetase. Translation of specific messenger ribonucleic acid in a cell-free system derived from rabbit reticulocytes. Journal of Biological Chemistry 252, 30283034.

Pateman, J. A. (1970). Regulation of synthesis of glutamate dehydrogenase and glutamine synthetase in microorganisms. Biochemical Journal 115, 769-775.

Quinto, C., Mora, J. \& Palacios, R. (1977). Neurospora crassa glutamine synthetase. Role of enzyme synthesis and degradation on the regulation of enzyme concentration during exponential growth. Journal of Biological Chemistry (in the Press).

Sánchez, S., Martínez, L. \& Mora, J. (1972). Interactions between amino acid transport systems in Neurospora crassa. Journal of Bacteriology 112, 276-284.

SARKAR, P. K. \& Griffith, B. (1976). Messenger RNA for glutamine synthetase: its partial purification, translation in a cell-free system and its regulation by hydrocortisone. Biochemical and 
Biophysical Research Communications 68, 675681.

Sims, A. P., Toone, J. \& Box, V. (1974a). The regulation of glutamine synthesis in the food yeast Candida utilis: the purification and subunit structure of glutamine synthetase and aspects of enzyme deactivation. Journal of General Microbiology 80, 485-499.

Sims, A. P., Toone, J. \& Box, V. (1974b). The regulation of glutamine metabolism in Candida utilis: mechanisms of control of glutamine synthetase. Journal of General Microbiology 84, 149-162.

Stadtman, E. R. \& GinsburG, A. (1974). The glutamine synthetase of Escherichia coli: structure and control. In The Enzymes, vol. 10, pp. 755-807. Edited by P. D. Boyer. New York: Academic Press.

Streicher, S. L., Bender, R. A. \& Magasanik, B. (1975). Genetic control of glutamine synthetase in Klebsiella aerogenes. Journal of Bacteriology 121, 320-331.

Tiemeier, D. C. \& MilmaN, G. (1972). Regulation of glutamine synthetase in cultured Chinese hamster cells. Journal of Biological Chemistry 247, 5722-5727.

Tyler, B., De Leo, A. \& Magasanik, B. (1974). Activation of transcription of hut DNA by glutamine synthetase. Proceedings of the National Academy of Sciences of the United States of America 71, 225-229.

VOGEL, H. J. (1964). Distribution of lysine pathways among fungi: evolutionary implications. American Naturalist 98, 435-446.

Weglenski, P. \& TyleR, B. (1977). Regulation of gln A messenger ribonucleic acid synthesis in Klebsiella aerogenes. Journal of Bacteriology 129, 880-887.

Wohlhueter, R. M., Schutt, H. \& Holzer, H. (1973). Regulation of glutamine synthetase in vivo in Escherichia coli. In The Enzymes of Glutamine Metabolism, pp. 45-64. Edited by S. Prusiner \& E. R. Stadtman. New York: Academic Press.

YeMM, E. W. \& CockING, E. C. (1955). The determination of amino acids with ninhydrin. Analyst 80, 209-214. 